\title{
A dry and fully dispersible bacterial cellulose formulation as a stabilizer for oil-in-water emulsions
}

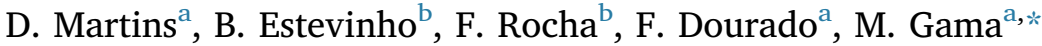 \\ ${ }^{a}$ CEB- Centre of Biological Engineering, Universidade do Minho, Campus de Gualtar, 4710-057 Braga, Portugal \\ ${ }^{\mathrm{b}}$ LEPABE - Laboratory for Process Engineering, Environment, Biotechnology and Energy, Faculdade de Engenharia da Universidade do Porto, Rua Dr. Roberto Frias, 4200- \\ 465 Porto, Portugal
}

\section{A R T I C L E I N F O}

\section{Keywords:}

Bacterial cellulose

Spray-dryer

Oil-in-water emulsions

Interfacial tension

\begin{abstract}
A B S T R A C T
Bacterial cellulose (BC) is an emerging alternative to plant cellulose in different applications. Several works demonstrated the potential of never-dried BC; however, envisioning real industrial applications, a dry product retaining its functional properties upon rehydration is preferable.

A dry and completely redispersible formulation of BC with carboxymethyl cellulose (CMC) was prepared by Spray-drying. The obtained material showed a Zeta Potential of $(-67.0 \pm 3.9) \mathrm{mV}$, a Dv(50) of $(601 \pm 19.7)$ $\mu \mathrm{m}$ and was able to decrease the oil/water interface energy.

The dry BC:CMC formulation was employed as a stabilizer in oil-in-water emulsions, in parallel with commercial plant celluloses and Xanthan gum. The emulsions were monitored over time by optical microscopy and characterized by rheological measurements. BC:CMC effectively stabilized emulsions against coalescence and creaming, at a concentration of $0.50 \%$ - contrarily to other commercial dry celluloses - due to the Pickering effect and to the structuring of the continuous phase, as seen with Cryo-SEM.
\end{abstract}

\section{Introduction}

Emulsions may be stabilized by particles (Pickering effect) instead of surfactant amphiphilic molecules. Organic solid particles have shown to stabilize liquid-liquid interfaces when bearing a contact angle around $90^{\circ}$ at the interface. These particles irreversibly adsorb at the interface, forming a layer around the surface of the disperse phase droplets that acts as a mechanical barrier, preventing coagulation and coalescence phenomena (Binks, 2002; Lam, Velikov, \& Velev, 2014). A very small concentration of particles - enough to cover only a fraction of the interfacial area - may suffice to stabilize the emulsion. When an excess of particles remains in the continuous phase, they interact with each other and can form a three-dimensional structure, further enhancing the stabilization effect by steric hindrance. Also, the viscosity of the continuous phase increases, providing higher support to the disperse phase droplets, reducing coalescence and creaming (thus improving long-time storage) (Binks, 2002; Chevalier \& Bolzinger, 2013; Lam et al., 2014).

Hydrocolloidal microcrystalline cellulose (MCC) from plant sources is widely used in the food industry to regulate the stability, texture, rheology and organoleptic properties (Dourado et al., 2016). Many works refer to the use of cellulosic particles for oil-in-water Pickering emulsions stabilization (Bai, Huan, Xiang, \& Rojas, 2018, 2019; Capron \& Cathala, 2013; Cherhal, Cousin, \& Capron, 2016; Hu, Ballinger, Pelton, \& Cranston, 2015; Niu et al., 2018; Winuprasith \& Suphantharika, 2015). Cellulose particles are suitable for stabilizing Pickering emulsions because they have both hydrophilic and hydrophobic regions within the cellulose crystal structure (Kalashnikova, Bizot, Cathala, \& Capron, 2012; Yamane et al., 2006). Some work has also been done with never-dried BC (Kalashnikova, Bizot, Cathala, \& Capron, 2011; Ougiya, Watanabe, Morinaga, \& Yoshinaga, 1997; Paximada, Koutinas, Scholten, \& Mandala, 2016; Paximada, Tsouko, Kopsahelis, Koutinas, \& Mandala, 2016; Zhai, Lin, Liu, \& Yang, 2018). However, for the sake of storage, economy and practicality, it is important that additives for food and cosmetic industry can be provided in their dried form. Drying cellulose originates a so called "hornified" product, due to the establishment of inter-chain hydrogen bonds that are hardly broken when the material is placed in contact with water again. The rehydration of these products and generation of colloidal particles requires a substantial input of energy (Butchosa \& Zhou, 2014; Zhao, Kapur, Carlin, Selinger, \& Guthrie, 2011). Acid hydrolysis mitigates this effect by imparting negative charges on the crystallites' surface which improve their stability in aqueous media (Zhai et al., 2018). Alternatively, co-drying with charged polysaccharides may be used.

\footnotetext{
* Corresponding author.

E-mail address: fmgama@deb.uminho.pt (M. Gama).
} 
Being a negatively charged polymer, CMC imparts a surface charge to cellulose fibres where it adsorbs, improving their dispersion due to electrostatic repulsions. Also, upon drying, the presence of a charged drying-aid prevents the formation of hydrogen bonds between cellulose polymer chains during water removal, avoiding hornification. This results in improved redispersion of the cellulose fibres when rehydrated, thus preserving and re-establishing the functional properties as those of the never-dried material (Agarwal, MacNaughtan, \& Foster, 2018; Butchosa \& Zhou, 2014; Naderi, Lindström, Sundström, \& Flodberg, 2015).

Dry commercial products of MCC and nano-crystalline cellulose (NCC) from plant sources are available, and fibrillary dry products have also been reported (Agarwal et al., 2018; Butchosa \& Zhou, 2014; Naderi et al., 2015). However, dry cellulose from bacterial source has only seldom been reported (Clasen, Sultanova, Wilhelms, Heisig, \& Kulicke, 2006; Pa'E et al., 2014), even more rarely in powder form (Amin, Abadi, \& Katas, 2014). Most of the reports consist in patents (as examples, Tammarate (1999); Watanabe et al. (2000); Yang et al. (2011); Yang, Sharma, Mohan, \& Kobzeff, 2001), which do not clearly show the rehydrating ability of the prepared materials nor analyse the post-processing retrieval of the functional properties (i.e. maintaining the ability to stabilize heterogeneous systems). Achieving a dry, rehydratable and functional product could be a step ahead in placing $\mathrm{BC}$ as a competitor in the hydrocolloid market, along with the existing plant celluloses and other widely used polysaccharides as Xanthan gum. In this work, a dry formulation of BC and CMC was prepared, which is fully rehydratable within few minutes using low energy stirring. These features are of utmost importance for the industry, as they impact on the operating costs, for hydrocolloidal microcrystalline cellulose requires high energy mixing for optimal functionalization. A benchmarking study with several commercially available cellulose dry products and Xanthan gum as emulsion stabilizers was performed, revealing the retrieval of the $\mathrm{BC}$ functionality after drying and rehydration, and its suitability as a stabilizer.

\subsection{Hypothesis}

Adding an appropriate amount of polyanionic CMC to low-charged BC increases the fibres surface charge, improving their dispersion due to electrostatic repulsions and preventing hornification upon drying. This effect allows for a complete rehydration and re-establishment of BC's functional properties, namely the ability to stabilize Pickering oilin-water emulsions. Due to their unique structure and high aspect ratio, BC fibres can supplant plant celluloses in the stabilization of oil-inwater emulsions.

\section{Materials and methods}

\subsection{Materials and reagents}

Carboxymethyl cellulose ( $90 \mathrm{kDa}$, degree of substitution of 0.7 ) was supplied by Acros Organics (New Jersey, USA), Xanthan gum was bought from Sigma (St. Louis, Missouri, USA), and isohexadecane was gently provided by Lanxess (Leverkusen, Germany). Colloidal MCC Avicel RT1133 (containing $11.9 \%$ CMC), non-colloidal MCC Avicel LM310 and non-colloidal MCC Novagel RCN15 (with $15 \%$ Guar gum) were provided by FMC Corporation (Philadelphia, Pennsylvania, USA). Hydrophilic sulphated cellulose nanocrystals, Celluforce NCC, was provided by Celluforce (Montreal, Quebec, Canada).

\subsection{BC:CMC preparation}

BC membranes (HTK Food CO. Ltd, Vietnam) were, at room temperature, washed in a $0.1 \mathrm{M} \mathrm{NaOH}$ solution, rinsed thoroughly with distilled water until the $\mathrm{pH}$ reached that of the distilled water and then wet ground using a Sammic fixed speed blender, model TR250 at 9000
Rpm (Sammic, S.L.). The solid fraction of the obtained pulp was determined and adjusted to $1 \%(\mathrm{~m} / \mathrm{v})$. The effect of different BC:CMC ratios on the dry materials redispersion was preliminarily studied and the optimal ratio was found to be 1:1. This proportion was selected to proceed with the experiments for giving the best redispersion results. Thus, to the $1 \% \mathrm{BC}$ pulp, the same volume of $1 \%(\mathrm{~m} / \mathrm{v})$ CMC (90 $\mathrm{kDa})$ was added, making up a 1:1 mixture (BC:CMC) of $1 \%$ total solids. This mixture was left under magnetic stirring overnight at room temperature and then autoclaved at $121^{\circ} \mathrm{C}$ for $20 \mathrm{~min}$. The formulation was then dried in a pilot Spray-Dryer (GEA Niro A/S Production Minor) with a $2 \mathrm{~mm}$ Nozzle (3.5 bar), using an inlet flow rate of approximately $10 \mathrm{~kg}$ / $\mathrm{h}$ of $1 \%$ BC:CMC mixture in water, inlet temperature of $210^{\circ} \mathrm{C}$ and outlet temperature of $115^{\circ} \mathrm{C}$. High temperatures were used to ensure a completely dry product in the outlet (since CMC and BC are very hydrophilic, and BC has high water holding capacity), to minimize losses by adhesion to the equipment walls and to minimize the processing time. This was possible due to cellulose's high thermal stability.

\subsection{Contact angles of $B C$ and $B C: C M C$}

$\mathrm{BC}$ and $\mathrm{BC}: \mathrm{CMC}$ dispersions $(0.50 \% \mathrm{~m} / \mathrm{v})$ were layered onto glass slides and dried at $37{ }^{\circ} \mathrm{C}$ to assure flat and smooth films. Contact angles were determined by the sessile drop method using Optical Contact Angle (OCA 20, DataPhysics) and SCA 20 Software module 22 (DataPhysics). Drops of $2 \mu \mathrm{L}$ of ultrapure (MilliQ) water were deposited on top of the films with a Hamilton $500 \mathrm{~mL}$ syringe and left in contact for $120 \mathrm{~s}$, at $20 \pm 1{ }^{\circ} \mathrm{C}$, while recording with the equipment's video camera. Movie records were analysed frame by frame to determine the contact angles over time. Glass slides without any film were used as control.

\subsection{Particles zeta potential and size measurements}

The Zeta Potential of the used celluloses was measured using a Zetasizer Nano ZS (Malvern Instruments Ltd.). Avicel and Novagel products $(1.5 \% \mathrm{~m} / \mathrm{v}$ in distilled water) were first activated, at room temperature, according to the manufacturer's recommendation, for $20 \mathrm{~min}$ at $20000 \mathrm{rpm}$ in a Unidrive X1000D homogenizer (CAT Scientific) with a T20 F Shaft and Generator assembly. The other celluloses were dispersed in distilled water at a concentration of $0.50 \%$ $(\mathrm{m} / \mathrm{v})$ and stirred with magnetic agitation $(20 \mathrm{~min}$ at $500 \mathrm{rpm})$, also at room temperature. All samples were further diluted to $0.1 \%$ in distilled water and analysed three times in a disposable folded capillary cell (Malvern Instruments).

The particles' size by volume of the different celluloses was determined using a Mastersizer 3000 particle size analyser equipped with a Hydro EV wet dispersion unit (Mastersizer 3000, Malvern Instruments Ltd.). Aqueous dispersions of BC, BC:CMC, activated and non-activated Avicel and Novagel products were analysed six times at an obscuration level between 10 and $20 \%$. Taking into account that these were nonspherical particles, Mie scattering model was used for the analysis and the refractive index of cellulose and water were assumed as 1.468 and 1.330 respectively (as provided by the software's database). For irregular shaped particles, the Mastersizer takes the volume of the particle and calculates the diameter of an imaginary sphere that is equivalent in volume. The particles size was then expressed as the Mass Median Diameter, $\operatorname{Dv}(50)$ (the size at which $50 \%$ of the sample is smaller and $50 \%$ is larger, considering the volume distribution), $\mathrm{Dv}(10)$ and $\mathrm{Dv}(90)$ (the size of particle below which $10 \%$ and $90 \%$ of the sample lies, respectively).

\subsection{Interfacial tension measurements}

\subsubsection{Pendant drop method}

Interfacial tension was measured with the pendant drop method using Optical Contact Angle (OCA 20, DataPhysics), and SCA 20 
Software module 22 (DataPhysics). Two $\mathrm{mL}$ of isohexadecane was placed on a disposable optical polystyrene macro standard fluorescence cuvette $(1 \mathrm{~cm} \times 1 \mathrm{~cm} \times 4.5 \mathrm{~cm})$ (Labbox). A Hamilton $500 \mathrm{~mL}$ syringe ( $0.71 \mathrm{~mm}$ outer needle diameter) containing the aqueous sample suspensions (heavier phase) was introduced in the cuvette, with the needle always at the same depth. First, maximum drop volume was determined for each sample. For each drop, profile extraction and IFT calculation were made automatically, 10 times per minute until 25 readings, in triplicate for each sample and at $20 \pm 1{ }^{\circ} \mathrm{C}$.

\subsubsection{Du Noüy ring method}

A K20 Force Tensiometer (Kruss) with a RI21 platinum-iridium alloy wire ring was used for the Du Noüy ring method. BC:CMC dispersions density was assumed the same as that of the distilled water at $20^{\circ} \mathrm{C}, 1.00 \mathrm{~g} / \mathrm{mL}$, and isohexadecane's density was $0.79 \mathrm{~g} / \mathrm{mL}$ at $20^{\circ} \mathrm{C}$. Ten $\mathrm{mL}$ of each phase were placed in a glass sample vessel $(70 \mathrm{~mm}$ outer diameter), and analyses were performed according to the equipment's manual. Readings were performed in triplicate for each sample, at $21 \pm 1{ }^{\circ} \mathrm{C}$.

\subsubsection{Statistical analysis}

Statistical analysis was performed using GraphPad Prism 5 (GraphPad Software). Results were expressed as mean \pm standard deviation. A one-way analysis of variance (ANOVA) was performed, followed by Tukey's Multiple Comparison Test, to establish the significance of differences.

\subsection{Emulsions preparation}

MCC (Avicel and Novagel products) were activated as described in Section 2.4 before dilution. Celluforce, BC:CMC, CMC and Xanthan were dispersed in distilled water with magnetic stirring $(20 \mathrm{~min}$ at $500 \mathrm{rpm}$, room temperature), in the required amounts.

Isohexadecane-in-water emulsions (10:90) were each prepared in the presence of $0.50 \%$ of the different polymers, in a total volume of $100 \mathrm{~mL}$. Samples were homogenized in a Unidrive X1000D for $4 \mathrm{~min}$ at a speed of $20000 \mathrm{rpm}$ and stored at room temperature. Additionally, emulsions with lower BC:CMC concentrations - $0.25 \%$ and $0.1 \%$ - were prepared in the same conditions. Photos were taken at different timepoints after preparation, for at least one month.

$\mathrm{BC}$ alone was not used in these assays because it aggregates and creates fibre bundles under high-shear stirring/mixing.

\subsection{Microscopy}

For optical microscopy observations, a drop of each sample was placed on a slide, coversliped and visualized on an Olympus BX51 fluorescence microscope using bright field.

Spray-dried BC:CMC observation was performed using a desktop Scanning Electron Microscope (SEM) coupled with energy-dispersive X- ray spectroscopy analysis (Phenom ProX, Phenom-World BV). Samples were added to aluminium pin stubs with electrically conductive carbon adhesive tape and coated with $2 \mathrm{~nm}$ Au prior to analysis.

Cryo-SEM observations were performed in the Laboratory for Scanning Electron Microscopy and X-Ray Microanalysis, at Materials Centre of the University of Porto (CEMUP), using a High-resolution Scanning Electron Microscope (JEOL JSM 6301 F) with X-Ray Microanalysis (Oxford INCA Energy 350) and CryoSEM experimental facilities (Gatan Alto 2500). Each sample was rapidly cooled in subcooled nitrogen and transferred under vacuum to the cold stage of the preparation chamber. The specimen was fractured, sublimated for $120 \mathrm{~s}$ at $-90^{\circ} \mathrm{C}$, and coated with $\mathrm{Au} / \mathrm{Pd}$ by sputtering for $50 \mathrm{~s}$ and with $12 \mathrm{~mA}$ current. The sample was then transferred into the SEM chamber and observed at a temperature of $-150{ }^{\circ} \mathrm{C}$.

\subsection{Rheological analysis of the emulsions}

Rheological analysis of the emulsions was performed in a controlled stress rheometer (DHR-1, TA instruments) with TRIOS Software (TA Instruments) at $25^{\circ} \mathrm{C}$ using a cone and plate geometry $\left(60 \mathrm{~mm}, 2.006^{\circ}\right.$ cone angle, $64 \mu \mathrm{m}$ gap). Samples shear stress and viscosity were measured in triplicate by flow sweep tests at increasing shear rates $(0.01$ to $1000 \mathrm{~s}^{-1}$ ). Oscillatory strain sweep tests were carried out to determine the sample's linear viscoelastic region (LVR) at a frequency of $1 \mathrm{rad} / \mathrm{s}$ and strain amplitude from 0.1 to $100 \%$. Oscillatory frequency sweep tests were performed in triplicate at a strain within the LVR $(0.25 \%$ strain), with angular frequency ranging from 0.1 to $100 \mathrm{rad} / \mathrm{s}$.

\section{Results and discussion}

CMC adsorbs onto and coats BC fibres in a water suspension, due to structural similarities that allow cooperative hydrogen bonding between the free cellulose segments on the CMC backbone and the cellulose fibre surfaces (Ahola, Myllytie, Österberg, Teerinen, \& Laine, 2008; Kargl et al., 2012; Laine, Lindstrom, Bremberg, \& GladNordmark, 2000). CMC is also responsible for preventing further fibre aggregation during the drying process - acting as co-drying and dispersant agent, due to its negative charge that is imparted onto the $\mathrm{BC}$ fibres, resulting in better redispersion owing to electrostatic repulsion forces (Butchosa \& Zhou, 2014; Naderi et al., 2015). Thus, when rehydrated, the BC fibres remain well separated and the gel recovers its original well dispersed structure and rheological properties. We observed that the spray-dried BC:CMC formulation reported herein could actually be completely redispersible in water at a concentration of 0.50 $\%(\mathrm{~m} / \mathrm{v})$, through simple magnetic stirring at $500 \mathrm{rpm}$ for $5 \mathrm{~min}$. To the best of our knowledge, this is the first report on co-drying BC and CMC into a dry formulation with such excellent water redispersion (Fig. 1A/ B).

Pa'E et al. (2014) tested different drying methods of BC membranes, but these samples were not ground or powdered, and only the swelling
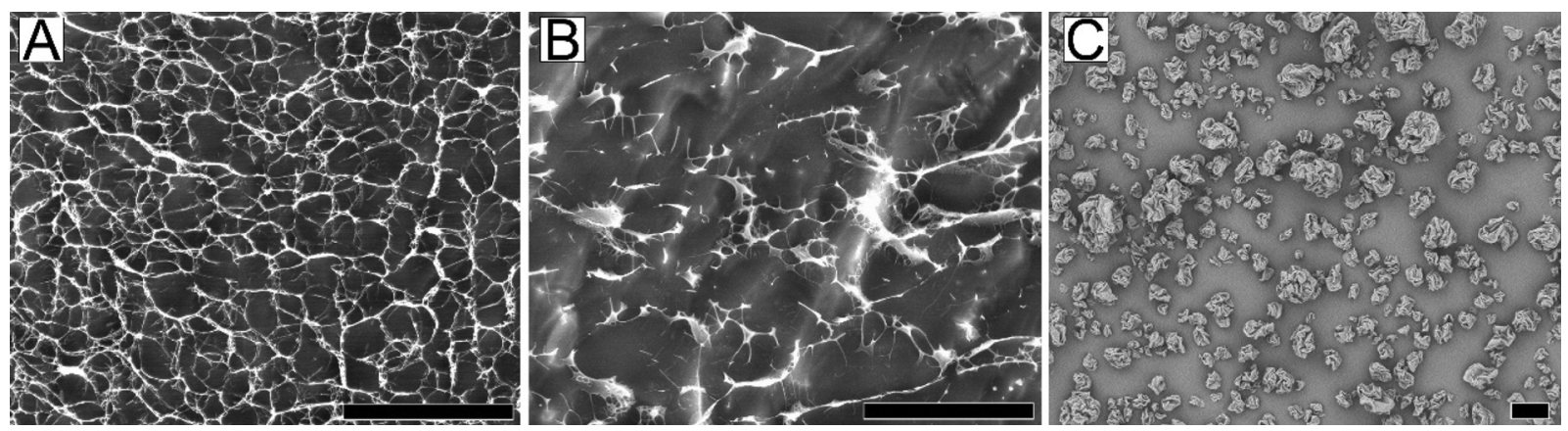

Fig. 1. Cryo-SEM images (2000X magnification) of (A) $0.50 \%$ non-dried BC:CMC; (B) $0.50 \%$ dried and redispersed BC:CMC; (C) SEM image (890X magnification) of spray-dried BC:CMC. All black scale bars correspond to $20 \mu \mathrm{m}$. 
ability was assessed. Amin et al. (2014) prepared dry powders with blended $\mathrm{BC}$ and acid treated $\mathrm{BC}$ by freeze-drying or spray-drying, reporting limited swelling index and water retention capacity values after redispersion, as compared to the water retention capacity of the neverdried BC.

In a similar approach to ours, Butchosa and Zhou (2014) used a $250 \mathrm{kDa} C M C$ (DS $=0.90$ ) to prepare water-redispersible plant cellulose nanofibrils (CNFs). After high-shear mixing with Ultra-turrax, heat treatment and oven drying, a fully water-redispersible and stable suspension was obtained, preserving the original properties of never dried CNFs (namely the viscosity). However, the reported resuspension process requires magnetic stirring overnight followed by mixing with an Ultra-turrax for $15 \mathrm{~min}$, thus requiring much more energy and time than the here reported for the BC:CMC formulation. Later, Lindstrom et al. (2015) using also nanofibrillated cellulose from wood pulp (lowcharged), were able to prepare a redispersible dry product retaining "close-to-maintenance" rheological properties, adding low amounts of CMC (1\%) and a low-shear mixing protocol.

Fig. 1 shows Cryo-SEM micrographs of the BC:CMC mixture before drying (A), after redispersion in water (B) (through magnetic stirring) and also a SEM micrograph of the spray-dried powder (C). The redispersed BC:CMC presents a good dispersion at the fibre level as observed at the Cryo-SEM (Fig. 1B), although not as homogeneous as the one obtained before drying, some small aggregates being detectable. Nevertheless, considering the ease and swiftness of the redispersion ( $5 \mathrm{~min}$ under $500 \mathrm{rpm}$ ), the result is rather promising. Figure A (Supplementary Information) shows the microscopical appearance (rather homogeneous) of the dry and redispersed material in contrast with the never-dried BC fibres without CMC.

Several plant-derived celluloses were used in parallel as a benchmarking study, varying in size, morphology and chemical modification: colloidal Avicel RT1133 and non-colloidal Avicel LM310 are used as stabilizers of emulsions and suspended particles, and also texture modifiers for cosmetics or food products and beverages; Novagel RCN15 is recommended as fat replacer and as a rheology modifier in food products; finally, Celluforce $\mathrm{NCC}^{\circledR}$ has a vast recommended application spectra - for reinforcing Agent in Textiles and additive in thermoplastic composites, adhesives and paints, personal care products and food and beverages to improve texture and suspension qualities. All these products are commercially available, and this information is provided by the suppliers in the materials' datasheets and catalogues. Microscopic images of these products can be found in Figure B (Supplementary Information).

\subsection{Assessment of the surface hydrophilicity by contact angles measurement}

The contact angle of a water drop deposited on a surface depends on the material's hydrophobicity. Fig. 2 shows the contact angles of water with BC and BC:CMC.

An equilibrium contact angle was not observed (not even in glass), probably due to water evaporation (as the relative humidity of the room was not controlled) and in the case of polysaccharides, also due to water absorption and/or spreading. As observed in Fig. 2, for BC films the contact angle changes from over $80^{\circ}$ to less than $40^{\circ}$ in just $10 \mathrm{~s}$, further dropping to around $20^{\circ}$, clearly demonstrating the material's hydrophilicity. In the case of BC:CMC films the contact angle remained above $40^{\circ}$. This is a bit surprising, since CMC is a water-soluble polymer and could be expected to improve the materials hydrophilicity; however, the results suggest that water spreading and/or absorption on $\mathrm{BC}$ was more favourable than on BC:CMC. In both cases, the materials are highly hydrophilic.

\subsection{Surface charge assessment through Zeta Potential measurements}

The Zeta Potential is a stability indicator for colloidal suspensions: samples showing highly positive or negative Zeta Potential ( $>|30| \mathrm{mV}$ ) will have a lower tendency to aggregate and flocculate, owing to interparticle repulsion forces. Table 1 shows the Zeta Potential values for the used materials.

Although not included in Table 1, CMC and Xanthan gum are known to be negatively charged given the presence of carboxylic groups. Novagel is a mixture of cellulose with Guar gum, a cationic polysaccharide, which is likely to neutralize the anions that adsorb onto solid surfaces in aqueous suspensions, hence the almost neutral Zeta Potential. Celluforce's significant negative charge is due to the sulphate groups at the surface of the fibres. Interestingly, products containing only cellulose - BC and Avicel LM310 - showed similar values of Zeta Potential (around $-20 \mathrm{mV}$ ). On the other hand, the formulations containing CMC present lower Zeta Potential (around -60 to $70 \mathrm{mV}$ ), indicating a good colloidal stability. As mentioned before, CMC imparts a negative charge on $\mathrm{BC}$ fibres, resulting in a more negative Zeta Potential of $\mathrm{BC}: \mathrm{CMC}$, comparing with $\mathrm{BC}$ alone. These results, however, should be regarded as merely indicative, due to the differences in size and shape among the different cellulose samples (the Zetasizer Nano ZS is mostly suited for particles from $5 \mathrm{~nm}$ to $10 \mu \mathrm{m}$ ). Nevertheless, overall, the values compare well with those reported in the literature, e.g. in the case of BC fibres and the BC:CMC formulation (Silva-Carvalho et al., 2019).

Table 1 also shows the results of median size distribution measurements of the materials, by volume, or the size indicated by the supplier. BC was characterized in the never-dried form, and BC:CMC after drying and redispersion in water. The presence of CMC (in the $\mathrm{BC}$ :CMC formulation) decreased the value observed for the $\mathrm{BC}$ fibres' median size, which is most probably due to the improved dispersion of BC in the presence of CMC. Nevertheless, the Dv(50) value for this material is over 10-fold higher than the MCCs after the activation process (advised by the manufacturer as a means to destroy aggregates). Indeed, as shown in Table 1 , the high energy mixing resulted in a decrease of the MCCs particle size, more noticeably in the case of Avicel LM310 and Novagel RCN15 (Figure B of the Supplementary Information).

\subsection{Interfacial tension}

The chosen biphasic o/w system is a challenging one, given the difference in density between the oily and aqueous phases, a main driving force for creaming and phase separation (Tadros, 2004). The lightweight of isohexadecane $\left(0.79 \mathrm{~g} / \mathrm{mL}\right.$ at $\left.20^{\circ} \mathrm{C}\right)$ favours its use in cosmetic formulations. Other oils, mainly vegetable oils used in food, have density values closer to that of water (e.g. sunflower oil, $0.922 \mathrm{~g}$ / $\mathrm{mL}$ (Lamas, Constenla, \& Raab, 2016). Nonetheless, this more demanding system allows to better assess the performance of the new presented material, BC:CMC.

The interfacial tension (determined by the pendant drop method) between isohexadecane and water was $(47.3 \pm 0.3) \mathrm{mN} / \mathrm{m}$, while for commercial sunflower oil and water is much lower $(27.7 \pm 0.6) \mathrm{mN} /$ m. Fig. 3 shows the results obtained using two different methods to determine the interfacial tension between water dispersions of the different materials and isohexadecane. The large size and non-colloidal nature of Novagel made it difficult to analyse by the Pendant Drop method. Furthermore, a control with wet-ground BC alone was impossible to perform given the tendency of the fibres to aggregate in bundles that could not pass through the syringe and would cling to the tensiometer ring, not providing reliable measurements.

The high viscosity of the $0.50 \%$ Xanthan gum dispersion made it impossible to analyse with the ring method. Using the pendant drop method, this problem was overcome by allowing the drop to equilibrate for a few minutes before starting the tension measurements. BC:CMC, CMC, Xanthan and Celluforce drops were clear and transparent, while Novagel and Avicel ones had an opaque appearance. BC:CMC and xanthan drops were less round-shaped, more elongated and smaller. 
A

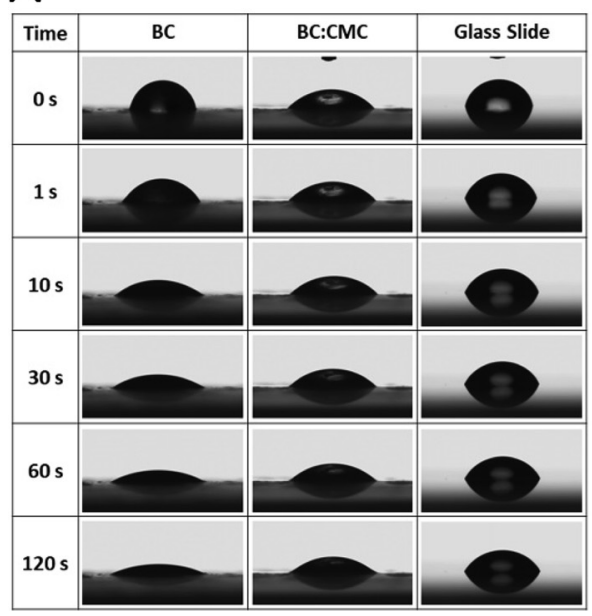

B

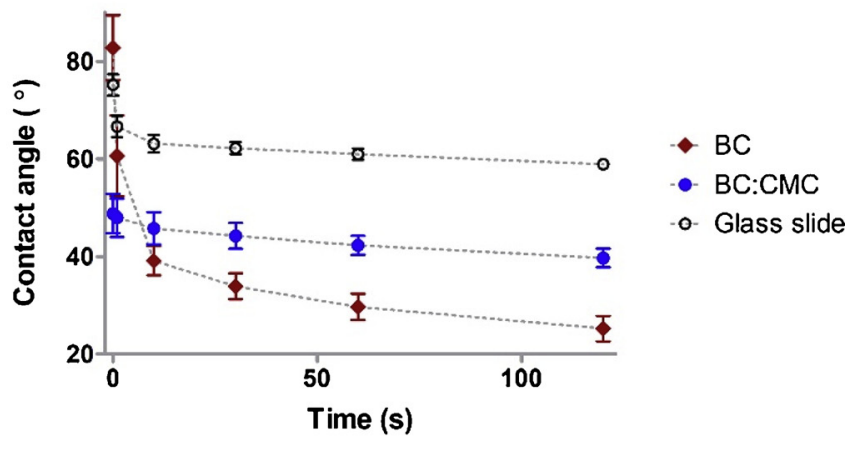

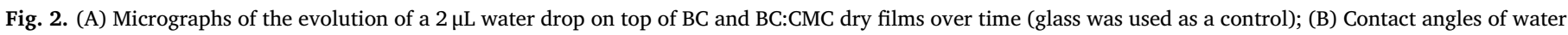
with BC and BC:CMC films over time, as determined by the sessile drop method.

Table 1

Zeta Potential (Z) and particle size of different cellulose aqueous suspensions, represented as the average and standard deviation.

\begin{tabular}{|c|c|c|c|c|c|c|c|}
\hline & & BC & BC:CMC & Avicel LM310 & Avicel RT1133 & Novagel RCN15 & Celluforce NCC \\
\hline $\mathrm{Z}(\mathrm{mV})$ & & $-23.3 \pm 0.9$ & $-67.0 \pm 3.9$ & $-22.6 \pm 0.7$ & $-64.9 \pm 0.5$ & $-1.4 \pm 0.2$ & $-51.3 \pm 2.3$ \\
\hline \multirow[t]{3}{*}{ Size $(\mu \mathrm{m})$} & $\operatorname{Dv}(10)$ & $184 \pm 5.26$ & $98.2 \pm 1.57$ & $\begin{array}{l}16.7 \pm 0.04^{\mathrm{a}} / \\
3.42 \pm 0.004^{\mathrm{b}}\end{array}$ & $3.02 \pm 0.01^{\mathrm{a}} / 2.76 \pm 0.03^{\mathrm{b}}$ & $\begin{array}{l}35.9 \pm 0.13^{\mathrm{a}} / \\
16.3 \pm 0.08^{\mathrm{b}}\end{array}$ & Diameter: $2.3-4.5 \mathrm{~nm}$; length: $44-108 \mathrm{~nm}^{\mathrm{c}}$ \\
\hline & $\operatorname{Dv}(50)$ & $1080 \pm 26.1$ & $601 \pm 19.7$ & $\begin{array}{l}38.6 \pm 0.09^{\mathrm{a}} / \\
10.3 \pm 0.02^{\mathrm{b}}\end{array}$ & $\begin{array}{l}10.4 \pm 0.10^{\mathrm{a}} / \\
7.9 \pm 0.04^{\mathrm{b}}\end{array}$ & $116 \pm 1.08^{\mathrm{a}} / 59.8 \pm 0.45^{\mathrm{b}}$ & \\
\hline & $\operatorname{Dv}(90)$ & $2360 \pm 16.5$ & $1850 \pm 51.4$ & $\begin{array}{l}76.2 \pm 0.20^{\mathrm{a}} / \\
26.4 \pm 0.14^{\mathrm{b}}\end{array}$ & $\begin{array}{l}55.9 \pm 2.37^{\mathrm{a}} / \\
222.5 \pm 0.55^{\mathrm{b}}\end{array}$ & $\begin{array}{l}304 \pm 4.60^{\mathrm{a}} / \\
189 \pm 4.38^{\mathrm{b}}\end{array}$ & \\
\hline
\end{tabular}

a- Before activation; b- After activation; c - Information provided by the supplier.

Although the interfacial tension values obtained by each method were not the same, the tendency is quite similar for the BC:CMC dispersions: the IFT significantly decreased with increasing BC:CMC concentration. A $0.50 \%$ CMC solution showed IFT values closer to water and very different from the BC:CMC dispersion at the same concentration. We can then impart the IFT decrease to the $\mathrm{BC}$ fibres in the formulation, since CMC alone is unable to induce such marked reduction of the interfacial forces between oil and aqueous phase.

The similarities between both methods are not so evident for the commercial products. For the pendant drop method (Fig. 3B), Celluforce and both Avicel products showed no significant differences from the water control; in the ring method (Fig. 3A) however, the Avicel celluloses seem to be able of lowering the IFT. While the ring method could be a more sensitive method for the plant celluloses, this was not the case for the BC:CMC and CMC samples.

Although the emulsion stabilizing ability of MCCs, NCCs and even $\mathrm{BC}$ have been reported, we could not find a systematic study on how and why these materials affect the IFT (Hu et al., 2015; Ougiya et al., 1997; Zhai et al., 2018). Overall, under the pendant drop method, xanthan yielded a slightly higher reduction in IFT than BC:CMC. On the other hand, it is clear that the BC:CMC formulation induced a greater decrease in the IFT than all of the commercial plant celluloses.

\subsection{Emulsion stability over time}

The visual aspect of the emulsions was recorded for several weeks (Figs. 4 and 5), allowing the observation of the creaming effect (whitish emulsified layer on the top of the vessel, separating from the continuous phase). In some cases, the separation of the oil phase is also detectable (broken emulsion). The oil droplets size was also assessed by optical microscopy observations. The emulsion with only CMC was unstable just 1 day after preparation, had substantial creaming and very large droplets of oil, these becoming quite evident after 30 days (Fig. 4). Different concentrations of BC:CMC were tested, showing that even small amounts of this formulation $(0.10 \%$ and $0.25 \%)$ are capable of preventing droplets aggregation and coalescence of the oil phase for up to 90 days, despite the visible creaming effect. Indeed, the size of the droplets remains constant throughout the assay. On the other hand, when using $0.50 \%$ of $\mathrm{BC}: \mathrm{CMC}$, no changes were detected and the emulsion remained fully stable (no creaming, no phase separation) (Fig. 4). When using $0.50 \% \mathrm{BC}: \mathrm{CMC}$, some larger oil microdroplets were observed from the beginning, most probably due to a decreased distribution of the shear forces during homogenization in a more viscous system. Similar results were attained by Winuprasith and Suphantharika (2015), using microfibrillated cellulose from mangosteen rind.

The formation of creaming just after 1 storage day was evident in all the commercial plant derived celluloses (Fig. 5). There is a direct correlation between particle size and Pickering emulsion droplet size. Smaller particles originate smaller emulsion droplet sizes, which ultimately translates into higher stability, because gravity has less effect on them (Niu et al., 2018). That is one of the reasons why Novagel, having large particles and lack of colloidal stability, is not recommended for Pickering stabilization, showing large coagulated oil droplets and phase separation (Fig. 5). Sulphated Celluforce, although being much smaller, has higher hydrophilicity and thus lower affinity for the oil phase, as pointed out by Kalashnikova et al. (2012), stabilizing the oil droplets only to some extent (under the conditions tested). Large size droplets appeared over time, and a thin layer of separated oil was also detected. For the two Avicel samples, LM301 preserved the small size of the $\mathrm{o} / \mathrm{w}$ droplets, whilst they slightly appeared to increase in the case of RT1133. Overall, among the plant derived celluloses, the smaller, nonmodified particles - Avicel celluloses - performed better, as they were able to prevent the oil droplets coagulation and oil separation, showing 


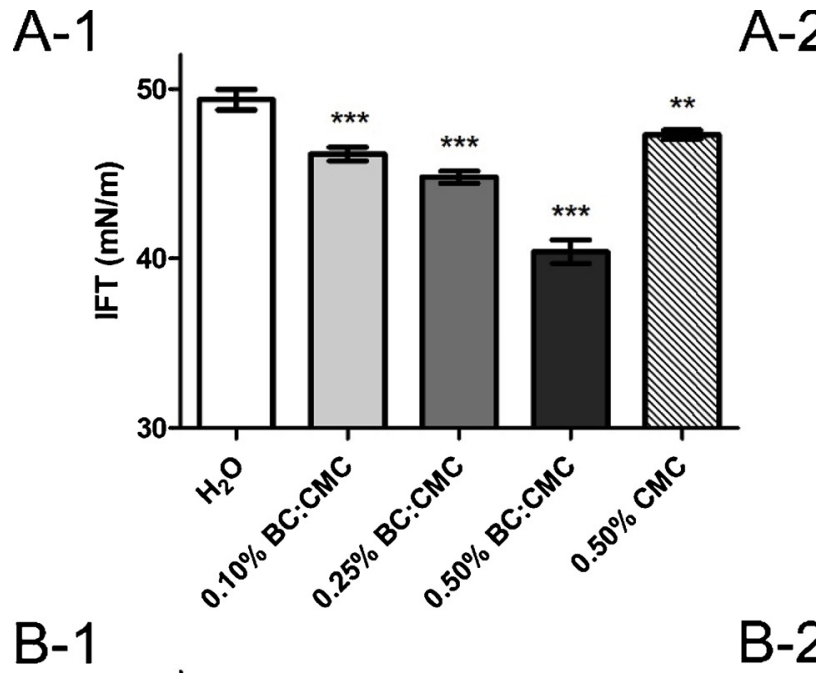

A-2
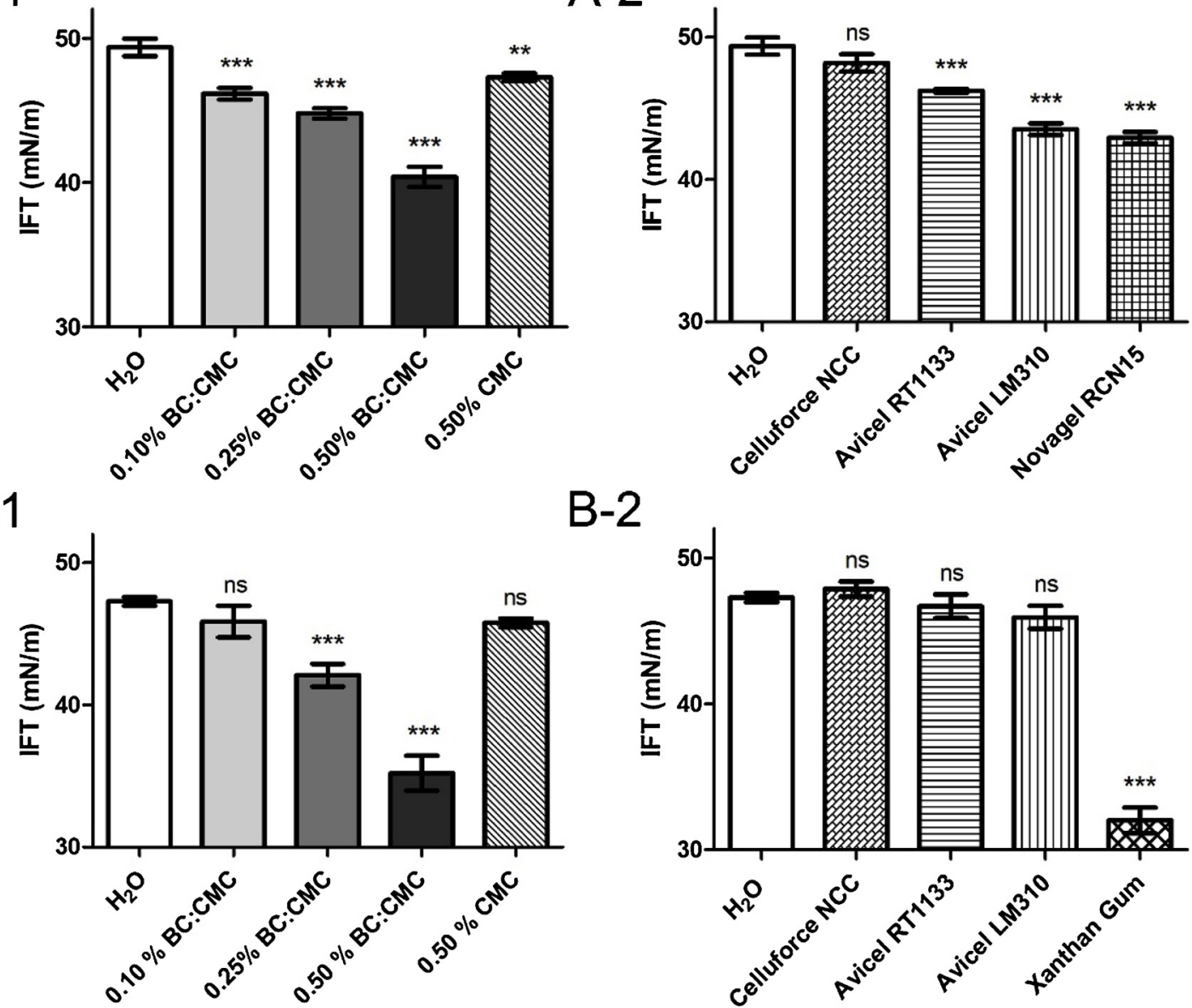

B-2

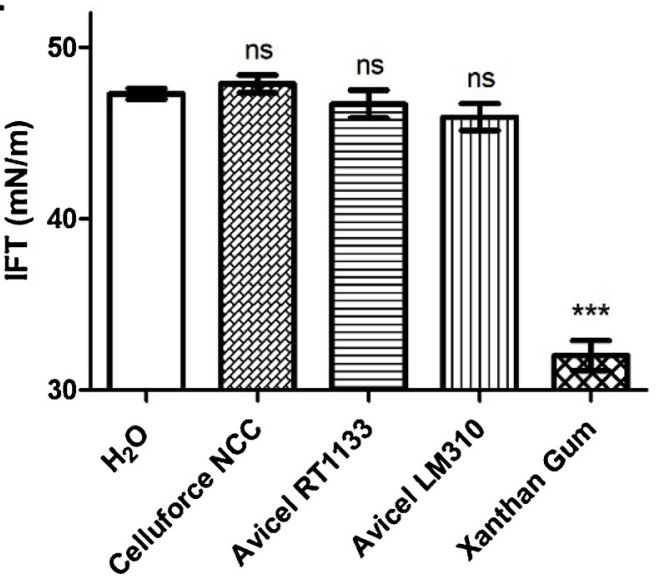

Fig. 3. Isohexadecane/water interfacial tension measurements performed by (A) Du Noüy Ring method and (B) Pendant Drop method, in the presence of (1) different concentrations of the BC:CMC dry formulation ( $0.10 \%, 0.25 \%$ and $0.50 \%$ ) and $0.50 \%$ CMC, and (2) $0.50 \%$ of plant celluloses (Avicel RT1133, Avicel LM310, Novagel RCN15, Celluforce NCC) and Xanthan gum. Results are the average of triplicate measurements and bars represent standard deviation. All the results were compared with the control $\left(\mathrm{H}_{2} \mathrm{O}\right)$ using one-way ANOVA and Tukey's Multiple Comparison Test (ns - not significant, ${ }^{*} \mathrm{p}<0.05$, ${ }^{* *} \mathrm{p}<0.01,{ }^{* * *} \mathrm{p}<0.001$ ).

why they are meant to be used for emulsion stabilization purposes.

Fibrillar materials with high aspect ratios generate entangled and disordered networks (Winuprasith \& Suphantharika, 2015). Although several celluloses with different sizes and surface charge were tested, they all were ineffective comparatively to BC:CMC formulations. The fibrous three-dimensional network generated by the swollen BC fibres (Fig. 6) even at lower concentrations $(<0.50 \%)$, allowed for a better control of the creaming effect. Thus, in addition to the Pickering effect, structuring of the water phase also contributed to the oil droplets' stabilization. Although cellulose microcrystals are also known for creating a network capable of structuring the continuous phase, relatively high concentrations are needed, since their aspect ratio (length/ width) is far lower than that that of $\mathrm{BC}$ nanofibres - in the range of 100 (as reported for single BC fibres prepared with aqueous counter collision) (Kondo, Rytczak, \& Bielecki, 2016). For colloidal MCC to form a stable gel network, concentrations of $1.5 \%$ are commonly used and a rest time is needed, following activation with high shear mixing, to achieve full structural equilibrium (Rudraraju \& Wyandt, 2005; Zhao et al., 2011). The same applies to nanocrystals - even BC nanocrystals which have lower aspect ratios than BC whole fibres (Kalashnikova et al., 2011). Thus, BC nanofibres, at much lower concentrations, being longer, flexible and thinner, have a structural advantage for covering the oil droplets and creating a mechanical network capable of sustaining and stabilizing the oil phase.

Xanthan gum is a standard polysaccharide ingredient in the food and cosmetic industries, used as thickener and stabilizing aid in many products. Xanthan gum emulsions were also stable and did not significantly change over time. Although showing large oil droplets from time zero (possibility also due to the higher viscosity of the continuous phase), they did not show aggregation or coalescence over time.

Cryo-SEM images of Fig. 5 clearly show the formation of an entangled network that develops in the continuous phase and around the disperse, ranging from a looser mesh at lower BC:CMC concentration (Fig. 6A), to a very dense, tight and structured network at higher concentration (Fig. 6C). BC's long but thin fibres, thus more flexible, can easily bend and shape to the interface. Several works have also shown the arrangement of cellulose fibres at the interface, covering the dispersed oil droplets (Cherhal et al., 2016; Kalashnikova et al., 2012; Ougiya et al., 1997; Winuprasith \& Suphantharika, 2015). However, only Winuprasith and Suphantharika (2015) mentioned the three-dimensional networks formed by fibres in the continuous aqueous phase and how they play a structural supporting role for the emulsion droplets. This effect strongly helps to improve the stability of the emulsion.

In addition to allowing the redispersion of the BC fibres, CMC may also contribute to the functional properties of the redispersed formulation, by improving the swelling and water dispersion of the $\mathrm{BC}$ fibres, which may be relevant to the emulsion stabilizing effect of the $\mathrm{BC}: \mathrm{CMC}$ formulation by structuring the continuous water phase.

\subsection{Rheological analysis}

The viscosity of BC:CMC emulsions (Fig. 7) increased with the concentration, as would be expected, and decreased with the increase in the shear rates, showing a characteristic shear-thinning behaviour. At 


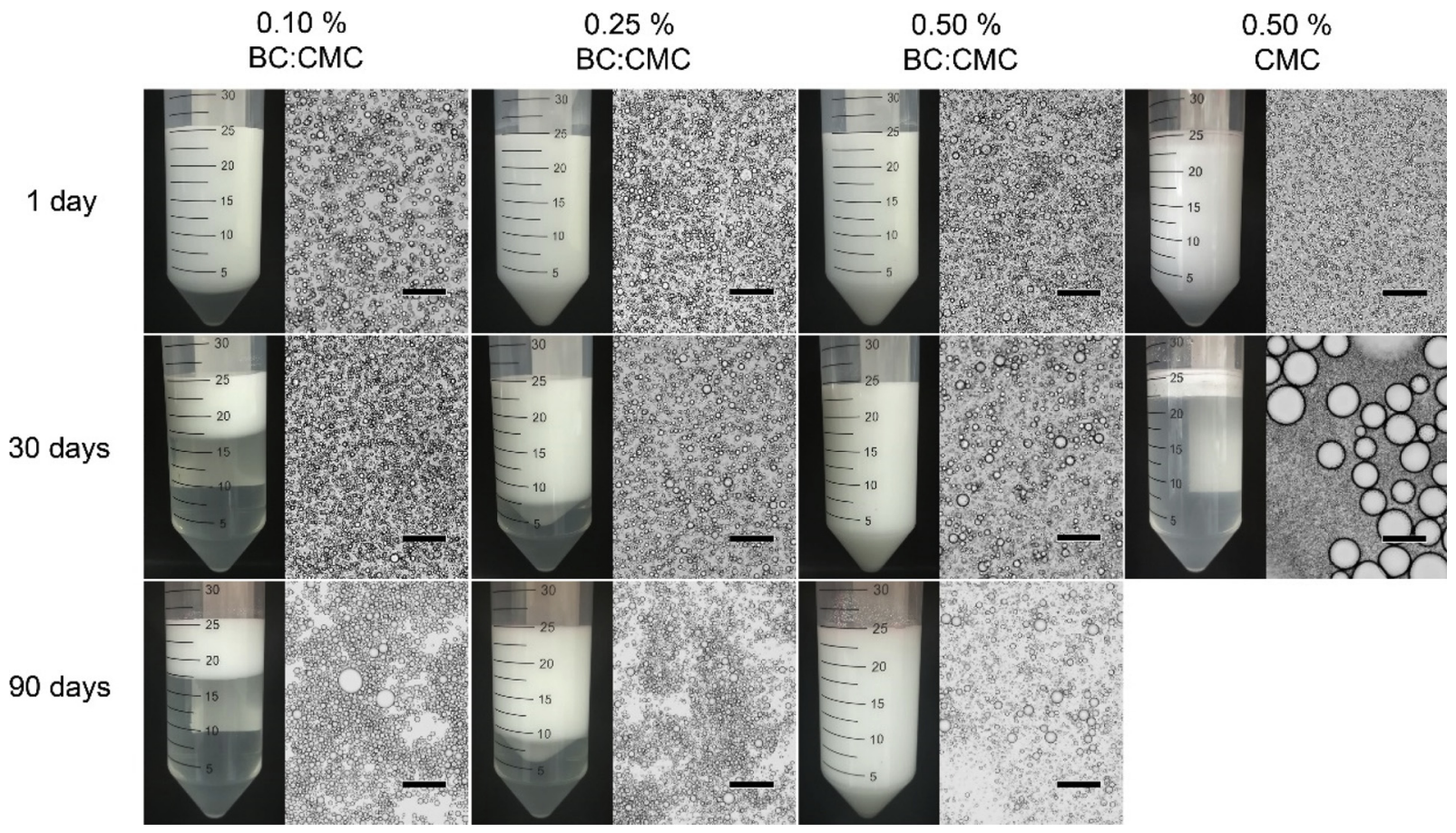

Fig. 4. Photographs and optical micrographs (10X magnification) of $10 \%$ isohexadecane-in-water emulsions prepared with different concentrations of BC:CMC dry formulation $(0.10 \%, 0.25 \%$ and $0.50 \%)$ and with $0.50 \%$ CMC, taken 1 day after preparation and after a storage time of 30 and 90 days, at room temperature. Black scale bars correspond to $100 \mu \mathrm{m}$.

$0.50 \%$ concentration, BC:CMC emulsions showed a rheologic behaviour closer to that of Xanthan gum emulsions, the later reaching a higher maximum viscosity value (126.2 Pa's versus 73.5 Pa's). The lower viscosity is not necessarily a disadvantage, as long as other rheologic parameters satisfy the demands for a stable emulsion. High viscosity might actually be an obstacle for proper sample homogenization, requiring higher shear stress, hence higher energy input, an economic disadvantage for industrial applications. As noted above, the size of the oil droplets was larger when using Xanthan gum.

It is also worth mentioning that the emulsion with $90 \mathrm{kDa} C M C$ alone has a very different profile and significantly lower viscosity. Thus, the viscosity of the BC:CMC dispersions is to be assigned mainly to the well dispersed BC fibres, as also noted by other authors (Zhao et al., 2011). Neither BC:CMC or Xanthan emulsions showed a yield stress value. The viscosity curves in Fig. 7 do not increase indefinitely towards the lower shear rates, and the emulsions flow at rest conditions (nearzero shear stress).
Dynamic mechanical rheological testing was applied to the more stable systems amongst the tested ones: Xanthan gum and BC:CMC (Fig. 8). First, a strain sweep was performed (data not shown) to establish the extent of the emulsions' linearity range - the LVR - where the storage modulus (G') and loss modulus (G') are approximately constant. The LVR was maintained up to $1 \%$ strain amplitude for the 0.50 $\%$ BC:CMC emulsions, and extended up to $10 \%$ for the Xanthan gum emulsions. A strain of $0.25 \%$ was chosen to proceed for the frequency sweep test.

There must be a sufficient degree of structure in an emulsion to avoid creaming and separation. The storage modulus G' is a good indicator of the emulsion's elastic (solid-like) behaviour coming from the inherent network structure, when it exists. When phases separate in an emulsion, it loses the solid-like character and becomes more fluid.

From Fig. 8, emulsions prepared with BC:CMC and Xanthan exhibited a predominant elastic behaviour within the LVR, since G' was higher than G". Interestingly, despite the higher viscosity on the

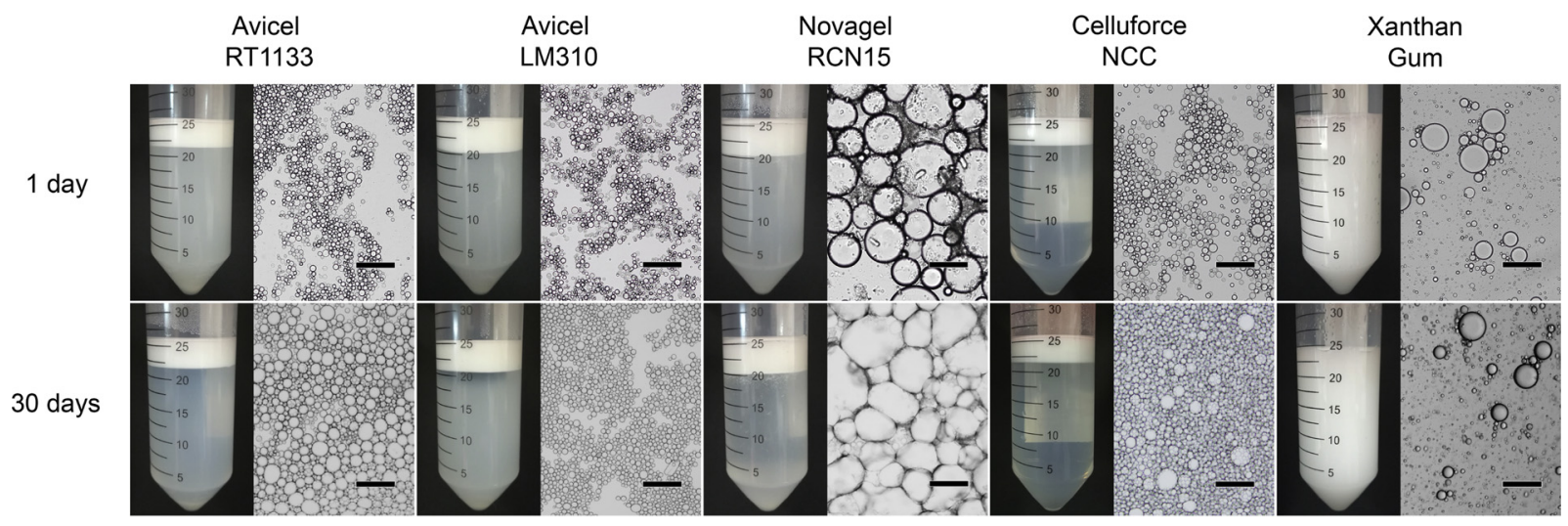

Fig. 5. Photographs and optical micrographs (10X magnification) of $10 \%$ isohexadecane-in-water emulsions prepared with $0.50 \%$ of different materials (Avicel RT1133, Avicel LM310, Novagel RCN15, Celluforce NCC and Xanthan gum), taken 1 day after preparation and after a storage time of 30 days at room temperature. Black scale bars correspond to $100 \mu \mathrm{m}$. 

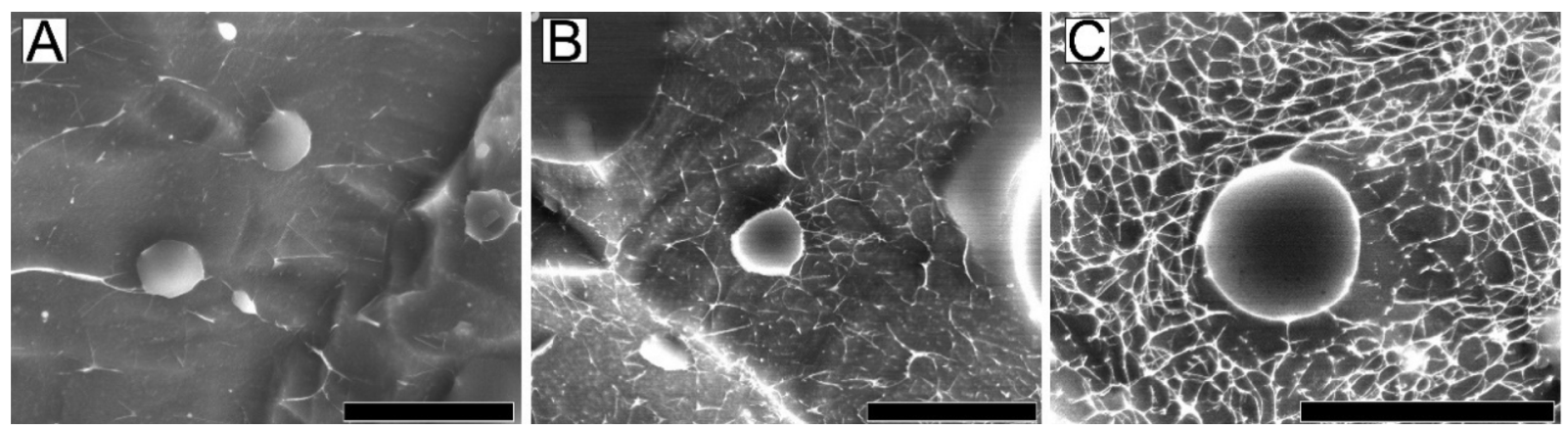

Fig. 6. Cryo-SEM images (different magnifications) of $10 \%$ isohexadecane-in-water emulsions prepared with (A) $0.10 \%$, (B) $0.25 \%$ and (C) $0.50 \%$ of the BC:CMC dry formulation in the day after preparation. All black scale bars correspond to $20 \mu \mathrm{m}$.

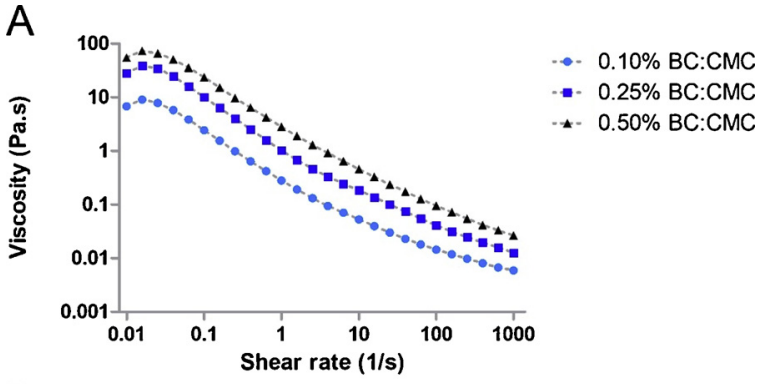

B

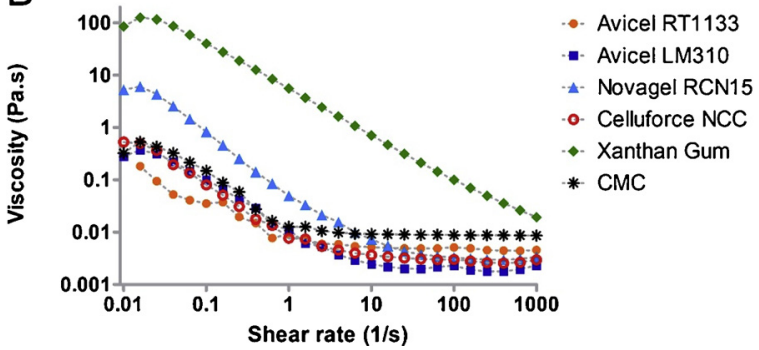

Fig. 7. Flow sweep curves of $10 \%$ isohexadecane-in-water emulsions prepared with (A) different concentrations of the BC:CMC dry formulation $(0.10 \%, 0.25$ $\%$ and $0.50 \%$ ); (B) $0.50 \%$ of different materials (Avicel RT1133, Avicel LM310, Novagel RCN15, Celluforce NCC, Xanthan gum and CMC), obtained from the average of triplicate samples.

Xanthan gum emulsions, the results point to a stronger network in the samples stabilized with BC:CMC, as G' is higher for BC:CMC emulsions than Xanthan. This could be due to a stiffer network created in the $\mathrm{BC}$ :CMC emulsions by the insoluble BC fibres.

As shown in Fig. 4, well separated oil droplets were still observed in the creaming layer of the emulsions processed with the plant celluloses, although the stability of these formulations was rather poor. It seems thus likely that these commercial celluloses are achieving some IFT reduction and acting as Pickering agents. However, the lack of aqueous phase structuring results in quick creaming and eventually phase separation. In turn, BC:CMC reduces more effectively the IFT, likely owing to the thinner and more flexible fibres, an effect that is reinforced by the relevant water structuring effect, as demonstrated by the CryoSEM and rheology studies. We speculate that the slightly lower hydrophilicity of the BC:CMC as compared BC alone, may be relevant to achieve a more favourable contact angle at the oil-water interface. In addition, we also hypothesize that CMC, by improving the fibres swelling by repelling each other due to the negative charges, may significantly contribute to the emulsions stabilization by promoting the three-dimensional structuring effect.

\section{Conclusion}

In short, the BC:CMC formulation used in $\mathrm{o} / \mathrm{w}$ emulsions showed to possess crucial characteristics for emulsion stability: surface charge, formation of a three-dimensional network, reduction of the interfacial energy and high viscosity (thickener). The ultrathin and very long BC fibres represent a radically different material as compared to some commonly available dry celluloses recommended as stabilizers, as the ones used as benchmark in this study, which are either soluble or lower aspect ratio hydrocolloidal cellulose particles. In general, these commercial dry products are obtained from plant/wood biomass, thus needing more processing steps to achieve a high purity and low size range, need much higher energy mixing to reach their full capabilities, which translate in lower efficiencies in the interfacial surface coverage and in the formation of a three-dimensional network for structuring the aqueous phase, in the case of emulsions. In this study, the prepared dry

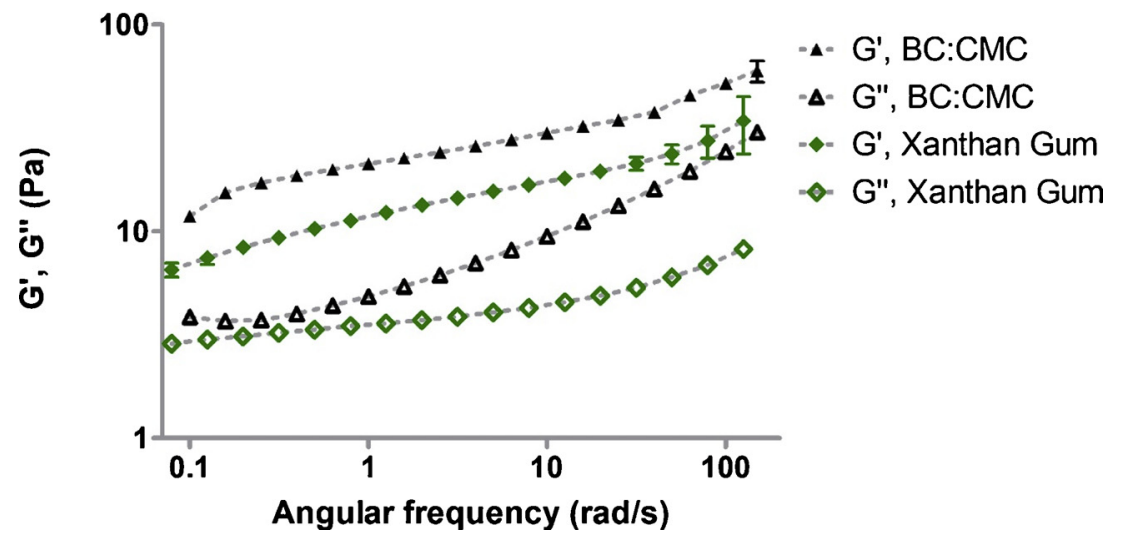

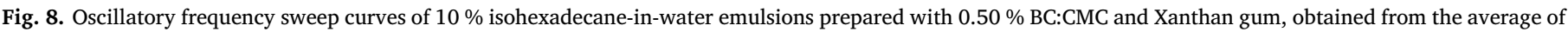
triplicate samples. Bars represent standard deviation. 
BC formulation was technically superior to the dry commercial celluloses used in parallel as benchmark: it showed better stabilizing performance and was easily and rapidly redispersible, with no need of activation or high energy processing prior to use. Due to its intrinsic structural and rheological properties, BC could be applicable as a thickener, stabilizer and texture modifier for food and cosmetic applications. At a concentration of $0.50 \%$, the dry BC:CMC formulation was able to effectively stabilize low density oil-in-water emulsions against coalescence or creaming for up to 90 days without the need to add any other emulsifying agents, thus confirming the potential of $\mathrm{BC}$ as a Pickering emulsions stabilizer.

\section{CRediT authorship contribution statement}

D. Martins: Investigation, Methodology, Formal analysis, Writing original draft. B. Estevinho: Resources, Writing - review and editing. F. Rocha: Resources, Writing - review and editing. F. Dourado: Conceptualization, Validation, Writing - review and editing, Supervision. M. Gama: Conceptualization, Writing - review and editing, Supervision.

\section{Acknowledgements}

This study was supported by the Portuguese Foundation for Science and Technology (FCT) under the scope of the strategic funding of UID/ BIO/04469 unit, COMPETE 2020 (POCI-01-0145-FEDER-006684) and BioTecNorte operation (NORTE-01-0145-FEDER-000004) funded by the European Regional Development Fund (ERDF) under the scope of Norte2020. FCT also supported this work by funding UID/EQU/00511/ 2019 unit, Project POCI-01-0145-FEDER-028715 funded by FEDER funds through COMPETE2020 and by national funds (PIDDAC) through FCT/MCTES, and Project NORTE-01-0145-FEDER-000005, funded by ERDF under the scope of NORTE 2020. The authors also acknowledge FCT for the PhD scholarship SFRH/BD/115917/2016 (Daniela Martins) and for the contract based on "Lei do Emprego Científico" (DL 57/ 2016) (Berta Estevinho).

\section{Appendix A. Supplementary data}

Supplementary material related to this article can be found, in the online version, at doi:https://doi.org/10.1016/j.carbpol.2019.115657.

\section{References}

Agarwal, D., MacNaughtan, W., \& Foster, T. J. (2018). Interactions between microfibrillar cellulose and carboxymethyl cellulose in an aqueous suspension. Carbohydrate Polymers, 185(January), 112-119. https://doi.org/10.1016/j.carbpol.2017.12.086.

Ahola, S., Myllytie, P., Österberg, M., Teerinen, T., \& Laine, J. (2008). Effect of polymer adsorption on cellulose. BioResources, 3(4), 1315-1328. https://doi.org/10.15376/ biores.3.4.1315-1328.

Amin, M. C. I. M., Abadi, A. G., \& Katas, H. (2014). Purification, characterization and comparative studies of spray-dried bacterial cellulose microparticles. Carbohydrate Polymers, 99, 180-189. https://doi.org/10.1016/j.carbpol.2013.08.041.

Bai, L., Huan, S., Xiang, W., \& Rojas, O. J. (2018). Pickering emulsions by combining cellulose nanofibrils and nanocrystals: Phase behavior and depletion stabilization. Green Chemistry, 20(7), 1571-1582. https://doi.org/10.1039/c8gc00134k.

Bai, L., Lv, S., Xiang, W., Huan, S., McClements, D. J., \& Rojas, O. J. (2019). Oil-in-water Pickering emulsions via microfluidization with cellulose nanocrystals: 1 . Formation and stability. Food Hydrocolloids, 96(January), 699-708. https://doi.org/10.1016/j. foodhyd.2019.04.038.

Binks, B. P. (2002). Particles as surfactants - similarities and differences. Current Opinion in Colloid \& Interface Science, 7, 21-41.

Butchosa, N., \& Zhou, Q. (2014). Water redispersible cellulose nanofibrils adsorbed with carboxymethyl cellulose. Cellulose, 21(6), 4349-4358. https://doi.org/10.1007/ s10570-014-0452-7.

Capron, I., \& Cathala, B. (2013). Surfactant-free high internal phase emulsions stabilized by cellulose nanocrystals. Biomacromolecules, 14, 291-296. https://doi.org/10.1021/ bm301871k.

Cherhal, F., Cousin, F., \& Capron, I. (2016). Structural description of the interface of pickering emulsions stabilized by cellulose nanocrystals. Biomacromolecules, 17, 496-502. https://doi.org/10.1021/acs.biomac.5b01413.

Chevalier, Y., \& Bolzinger, M. (2013). Emulsions stabilized with solid nanoparticles : Pickering emulsions. Colloids and Surfaces A, Physicochemical and Engineering Aspects, 439, 23-34. https://doi.org/10.1016/j.colsurfa.2013.02.054.
Clasen, C., Sultanova, B., Wilhelms, T., Heisig, P., \& Kulicke, W. M. (2006). Effects of different drying processes on the material properties of bacterial cellulose membranes. Macromolecular Symposia, 244, 48-58. https://doi.org/10.1002/masy. 200651204.

Dourado, F., Leal, M., Martins, D., Fontão, A., Rodrigues, A. C., \& Gama, M. (2016). Celluloses as food Ingredients/Additives: Is there a room for BNC? In M. Gama, F. Dourado, \& S. Bielecki (Eds.). Bacterial nanocellulose - From biotechnology to bioeconomy (pp. 123-133). Amsterdam, Netherlands: Elsevier B.V.

Hu, Z., Ballinger, S., Pelton, R., \& Cranston, E. D. (2015). Surfactant-enhanced cellulose nanocrystal Pickering emulsions. Journal of Colloid and Interface Science, 439, 139-148. https://doi.org/10.1016/j.jcis.2014.10.034.

Kalashnikova, I., Bizot, H., Cathala, B., \& Capron, I. (2011). New pickering emulsions stabilized by bacterial cellulose nanocrystals. Langmuir, 27, 7471-7479. https://doi. org/10.1021/la200971f.

Kalashnikova, I., Bizot, H., Cathala, B., \& Capron, I. (2012). Modulation of cellulose nanocrystals amphiphilic properties to stabilize Oil/Water interface. Biomacromolecules, 13, 267-275. https://doi.org/10.1021/bm201599j.

Kargl, R., Mohan, T., Bračč, M., Kulterer, M., Doliška, A., Stana-Kleinschek, K., et al. (2012). Adsorption of carboxymethyl cellulose on polymer surfaces: Evidence of a specific interaction with cellulose. Langmuir, 28(31), 11440-11447. https://doi.org/ 10.1021/la302110a.

Kondo, T., Rytczak, P., \& Bielecki, S. (2016). Bacterial NanoCellulose characterization. In M. Gama, F. Dourado, \& S. Bielecki (Eds.). Bacterial nanocellulose - From biotechnology to bio-economy (pp. 59-71). Amsterdam, Netherlands: Elsevier B.V.

Laine, J., Lindstrom, T., Bremberg, C., \& Glad-Nordmark, G. (2000). Studies on topochemical modification of cellulosic fibres. Nordic Pulp and Paper Research Journal, 15(3), 325-332. https://doi.org/10.3183/npprj-2003-18-03-p325-332.

Lam, S., Velikov, K. P., \& Velev, O. D. (2014). Pickering stabilization of foams and emulsions with particles of biological origin. Current Opinion in Colloid \& Interface Science, 19(5), 490-500. https://doi.org/10.1016/j.cocis.2014.07.003.

Lamas, D. L., Constenla, D. T., \& Raab, D. (2016). Effect of degumming process on physicochemical properties of sunflower oil. Biocatalysis and Agricultural Biotechnology, 6, 138-143. https://doi.org/10.1016/j.bcab.2016.03.007.

Naderi, A., Lindström, T., Sundström, J., \& Flodberg, G. (2015). Can redispersible lowcharged nanofibrillated cellulose be produced by the addition of carboxymethyl cellulose? Nordic Pulp and Paper Research Journal, 30(4), 568-577. https://doi.org/ 10.3183/npprj-2015-30-04-p568-577.

Niu, F., Han, B., Fan, J., Kou, M., Zhang, B., Feng, Z. J., et al. (2018). Characterization of structure and stability of emulsions stabilized with cellulose macro/nano particles. Carbohydrate Polymers, 199(June), 314-319. https://doi.org/10.1016/j.carbpol. 2018.07.025.

Ougiya, H., Watanabe, K., Morinaga, Y., \& Yoshinaga, F. (1997). Emulsion-stabilizing effect of bacterial cellulose. Bioscience, Biotechnology, and Biochemistry, 61, 1541-1545. https://doi.org/10.1271/bbb.61.1541.

Pa'E, N., Hamid, N. I. A., Khairuddin, N., Zahan, K. A., Seng, K. F., Siddique, B. M., et al. (2014). Effect of different drying methods on the morphology, crystallinity, swelling ability and tensile properties of Nata de coco. Sains Malaysiana, 43(5), 767-773. Retrieved from http://journalarticle.ukm.my/7159/1/16_Norhayati_PaÔÇÖe.pdf.

Paximada, P., Koutinas, A. A., Scholten, E., \& Mandala, I. (2016). Effect of bacterial cellulose addition on physical properties of WPI emulsions. Comparison with common thickeners. Food Hydrocolloids, 54, 245-254.

Paximada, P., Tsouko, E., Kopsahelis, N., Koutinas, A. A., \& Mandala, I. (2016). Bacterial cellulose as stabilizer of o/w emulsions. Food Hydrocolloids, 53, 225-232. https://doi. org/10.1016/j.foodhyd.2014.12.003.

Rudraraju, V. S., \& Wyandt, C. M. (2005). Rheological characterization of Microcrystalline Cellulose/Sodiumcarboxymethyl cellulose hydrogels using a controlled stress rheometer: Part I. International Journal of Pharmaceutics, 292, 53-61. https://doi.org/10.1016/j.ijpharm.2004.10.011.

Silva-Carvalho, R., Silva, J. P., Ferreirinha, P., Leitão, A. F., Andrade, F. K., da Costa, R. M. G., et al. (2019). Inhalation of bacterial cellulose nanofibrils triggers an inflammatory response and changes lung tissue morphology of mice. Toxicological Research, 35(1), 45-63. https://doi.org/10.5487/tr.2019.35.1.045.

Tadros, T. (2004). Application of rheology for assessment and prediction of the long-term physical stability of emulsions. Advances in Colloid and Interface Science, 109, 227-258. https://doi.org/10.1016/j.cis.2003.10.025.

Tammarate, P. (1999). US Pat. No. 5962676 - Processes for the Modification and Utilization of Bacterial Cellulose. The Thailand research Fund, Thailand.

Watanabe, K., Shibata, A., Ougiya, H., Hioki, N., \& Morinaga, Y. (2000). US Pat. No. 6153413 - Method for Processing Bacterial Cellulose. Bio-Polymer Research Co., Ltd, Japan.

Winuprasith, T., \& Suphantharika, M. (2015). Properties and stability of oil-in-water emulsions stabilized by microfibrillated cellulose from mangosteen rind. Food Hydrocolloids, 43, 690-699. https://doi.org/10.1016/j.foodhyd.2014.07.027.

Yamane, C., Aoyagi, T., Ago, M., Sato, K., Okajima, K., \& Takahashi, T. (2006). Two different surface properties of regenerated cellulose due to structural anisotropy. Polymer Journal, 38(8), 819-826. https://doi.org/10.1295/polymj.PJ2005187.

Yang, Z.-F., Morrison, N. A., Talashek, T. A., Brinkmann, D. F., DiMasi, D., \& Chen, Y. L. (2011). US Pat. No. 8053216B2 - Bacterial cellulose-containing formulations. CP Kelco U.S., Inc, United States.

Yang, Z.-F., Sharma, S., Mohan, C., \& Kobzeff, J. (2001). WO 01/05838A1 - process for drying reticulated bacterial cellulose without Co-agents. United States: Pharmacia Corporation.

Zhai, X., Lin, D., Liu, D., \& Yang, X. (2018). Emulsions stabilized by nanofibers from bacterial cellulose: New potential food-grade Pickering emulsions. Food Research International, 103, 12-20. https://doi.org/10.1016/j.foodres.2017.10.030.

Zhao, G. H., Kapur, N., Carlin, B., Selinger, E., \& Guthrie, J. T. (2011). Characterisation of the interactive properties of microcrystalline cellulose - Carboxymethyl cellulose hydrogels. International Journal of Pharmaceutics, 415, 95-101. https://doi.org/10. 1016/j.ijpharm.2011.05.054. 